\title{
A RUA DO OUVIDOR ENQUANTO TERRITÓRIO DO CARNAVAL PRODUZIDO PELAS GRANDES SOCIEDADES DO SÉCULO XIX
}

\author{
Dimitri Andrey Scarinci ${ }^{1}$ \\ Nilton Abranches Júnior ${ }^{2}$
}

\section{Resumo}

O presente trabalho trata da construção do território simbólico da Rua do Ouvidor, localizada na cidade do Rio de Janeiro, durante o período de carnaval no século XIX. Nessa época representava a principal centralidade da cidade, onde eram divulgadas as últimas inovações importadas da Europa. O objetivo geral do trabalho é compreender a construção de uma territorialidade sazonal, que se materializou no espaço da cidade do Rio de Janeiro nos dias de Carnaval. Parte-se do resgate das práticas das molhadelas comuns ao Entrudo, até chegar à constituição das Sociedades Carnavalescas, a partir do ano de 1855. Essas Sociedades se constituem em uma modificação no uso do espaço urbano da cidade, trazendo hábitos cunhados nos carnavais europeus como ideais de modernidade e civilidade que o jovem país independente procurava inserir no cotidiano da população da capital do país.

Palavras - chaves: Território, carnaval, Rua do Ouvidor, Rio de Janeiro.

\section{THE“OUVIDOR” STREET AS TERRITORY OF CARNIVAL PRODUCED BY THE BY THE “GRANDES SOCIEDADES” IN THE XIX CENTURY}

\begin{abstract}
The present work deals with the construction of the symbolic territory of "Ouvidor" street, located in the city of Rio de Janeiro, during the period of carnival in the 19th century. At this time it represented the main centrality of the city, where the latest innovations imported from Europe were divulged. The general objective of the work is to understand the construction of a seasonal territoriality, which materialized in the space of the Rio de Janeiro city in the days of Carnival. The work reviews the act of the "molhadelas" common to the "Entrudo", and goes to the "Sociedades Carnavalescas", by the year 1855. These were a modification in the use of the urban space of the city, bringing habits designed in the European carnivals as Ideals of modernity and civility that the young independent country sought to insert into the daily life of the population of the capital of the country.
\end{abstract}

Key words: Territory, carnival, Rua do Ouvidor, Rio de Janeiro.

\footnotetext{
${ }^{1}$ Graduando em Geografia pela Universidade do Estado do Rio de Janeiro. E-mail: dimitriscarinci@gmail.com.

${ }^{2}$ Professor Adjunto do Departamento de Geografia da UERJ/Maracanã e Professor colaborador do Programa de Pós-Graduação em Geografia da Universidade do Estado do Rio de Janeiro. E-mail: niltonabranches07@yahoo.com.br.
} 


\section{LA CALLE DEL “OUVIDOR” MIENTRA DEL TERRITORIO DEL CARNAVAL PRODUCIDO POR LAS “GRANDES SOCIEDADES” DEL SIGLO XIX}

\section{Resumen}

El presente trabajo trata de la construcción del território simbólico de la calle del "Ouvidor", ubicada em la ciudad, donde se divulgava las últimas innovaciones importadas de Euorpa. El objetivo general del trabajo es compreender la construcción de uma tenência temporal estacional, que se materializó em el espacio de la ciudad de Río de Janeiro em los días de carnaval. Se parte del rescate de las prácticas de las "molhadelas" comunes al Entrudo, hasta llegar a la constituición de las "Sociedades Carnavalescas", a partir del año 1855. Estas sociedades se constituyen em uma modificación en el uso del espacio urbano de la ciudad, trayendo hábitos acuñados en los caminos europeos como ideales de módernidad y civilidade que el joven país independiente buscaba inseguridad cotidiana de la poblácion de la capital del país.

Palavras claves: Territorio, carnaval, Rua do Ouvidor, Carnaval.

\section{CONSIDERAÇÕES INCIAIS}

O presente trabalho tem como objetivo estudar a Rua do Ouvidor através da perspectiva da construção de uma territorialidade sazonal, que se materializava no espaço da cidade do Rio de Janeiro durante o período de Carnaval na metade final do século XIX. A rua em questão está localizada no centro da cidade do Rio de Janeiro. Trata-se de uma das ruas mais antigas da cidade, por onde aconteceram importantes fatos da história do Brasil, e, consequentemente, da cultura dominante na Corte brasileira. A Rua do Ouvidor apresenta-se como a principal centralidade do período estudado, pois concentrava o comércio com características europeias, o pensamento intelectual em suas livrarias e cafés, entre outros diversos aspectos, sendo considerada uma vitrine social do país (GERSON, 1965, p.65). Essas características fazem da Rua do Ouvidor um importante objeto para o entendimento da organização espacial da cidade do Rio de Janeiro no século XIX.

Esse trabalho procura também investigar o passado do espaço urbano da cidade a partir de seus aspectos sociais, econômicos e políticos, aqui identificados como fundamentais para a compreensão da construção de um território específico durante os dias do Carnaval carioca. É importante ressaltar que a Rua do Ouvidor ainda existe no centro da cidade do Rio de Janeiro, atualmente com significados e usos muitos distintos do que se propõem demonstrar nesse trabalho. A Geografia tem a capacidade de estudar o mesmo recorte espacial 
em diferentes interpretações e realidades utilizando o geossímbolo, além da identidade, como uma ferramenta para uma análise do espaço e suas manifestações culturais em dimensões simbólicas (BONNEMEISON, 2002, p.99).

O marco temporal deste trabalho tem início no Carnaval de 1855quando se inaugura o desfile do Congresso das Sumidades Carnavalescas. Pela primeira vez há uma ocupação do espaço da cidade do Rio de Janeiro por uma manifestação cultural nos dias de carnaval, próxima das que vemos atualmente (MORAES, 1958, p.51). Com esse início, com base nos desfiles, o carnaval carioca passa a ganhar uma nova roupagem que vai angariar força nas décadas seguintes, até o surgimento das três sociedades carnavalescas mais famosas: Tenentes do Diabo, Fenianos e Democráticos. Desde então, o carnaval vem construindo os seus territórios festivos, como uma representação de síntese e soma de uso do tecido urbano (HAESBAERT, 2007, p.14).

Parte-se do pressuposto de que o carnaval apresenta-se como uma representação das classes sociais que compõem a sociedade. Nessa representação, se percebe que durante os festejos, os anseios e críticas sociais para as distintas realidades que compõem uma cidade, em outras palavras, é a síntese do cotidiano de um povo durante a folia através de suas práticas ou maneiras de fazer cotidianas (CERTEAU, 1998, p.83). Segundo Cunha (2001, p.88), o carnaval teve forte veiculação, através das sociedades carnavalescas, para educar e civilizar as camadas mais pobres da sociedade. Com isso havia a veiculação de que o país recém-independente buscava progresso e, reproduzia os ideais europeus de civilidade e modernidade.

Dentro dessa representação cultural, o carnaval passou por diferentes modificações até chegarmos ao carnaval das grandes sociedades. Vale ressaltar que os jogos de entrudo de herança portuguesa durante vários anos foram a principal manifestação carnavalesca. As molhadelas foram classificadas como violentas e posteriormente substituídas pelos bailes de máscaras importados da França, assim como a consolidação de ir à rua fantasiado no cortejo para o baile. O cortejo de saída para as ruas com o uso de fantasias remete aos carnavais italianos de Veneza, que junto com os bailes de máscaras franceses asseguraram e propagaram a ideia de carnaval legítimo, moderno e civilizado (FERREIRA, 2005, p.58). É nesse cortejo pelas ruas que começam a se configurar o seu uso como territórios do carnaval, o que acaba se consolidando com os desfiles das Grandes Sociedades. O uso da rua ganha atenção especial na configuração dos desfiles das sociedades, pois representava além da noção 
de ensinar a civilidade, uma demonstração do poder econômico e social que as Sociedades Carnavalescas exemplificavam. Os que não faziam parte desse grupo ficavam a margem desse carnaval. Quando estes terminavam, estas pessoas tomavam conta do espaço das ruas com os seus jogos populares como o entrudo e o surgimento de outras manifestações culturais, porém com total distinção do carnaval produzido pelas Sociedades (PEREIRA, 2004, p.122). Justificam-se assim as diferentes territorializações que o carnaval oferece em seus múltiplos espaços. Ao aplicarmos esse referido processo na Rua do Ouvidor, em conformidade com Haesbaert (2007, p.24), o mesmo corresponderia às etapas de apropriação, territorialidade sem território, princípio da multiplicidade e território como valor simbólico.

Para montar e estabelecer relações para construir o entendimento dos territórios produzidos pelo carnaval na Rua do Ouvidor e interpretar os costumes da sociedade carioca imperial, foram utilizados como fontes de informação a pesquisa o levantamento de notícias de jornais, a consulta de periódicos e de imagens da época estudada. As informações utilizadas se encontram disponibilizadas de forma gratuita na internet, graças ao sítio eletrônico de pesquisa da Fundação Biblioteca Nacional, nas seções específicas da Hemeroteca e Mapoteca digital. Em paralelo aos dados coletados, foi feita também uma revisão bibliográfica acerca do tema, com vistas de se criar a construção de um diálogo da Geografia com outras ciências.

\section{A CENTRALIDADE DA RUA DO OUVIDOR}

Milton Santos em “A Natureza do Espaço: Técnica e Tempo, Razão e Emoção” (2006, p.70), nos mostra que o espaço é construído de acordo com as necessidades específicas de cada sociedade em seu tempo, logo a cidade que conhecemos hoje é resultado de usos diferentes do praticados no passado. A cidade do Rio de Janeiro aqui estudada é um espaço urbano muito diferente do que se apresenta no início do século XXI. Sendo assim, torna-se necessário resgatar como era a organização espacial da cidade do Rio de Janeiro no passado, a fim de que se possibilite uma melhor compreensão do espaço estudado nessa pesquisa.

A configuração espacial urbana do Rio de Janeiro remetia as barreiras impostas pela natureza da topografia do seu sítio. O Rio de Janeiro do século XIX era concebido enquanto cidade como um tabuleiro de xadrez, composto pelas ruas e edificações, inserido entre os morros que delimitavam seu território (CARVALHO, 1990, p.67), conforme explicitado na figura 1. Estes morros eram o do Castelo, o da Conceição, o de São Bento e o de Santo 
Antônio. Os morros constituíam uma barreira à circulação dos ventos, o que conferia ao Rio de Janeiro um ar de cidade mal cheirosa e infecciosa (ABREU, 1996, pp.163-164). A formação real do seu espaço urbano enquanto capital imperial era bem distinta daquilo que se queria. Era vendida a imagem de um Brasil moderno e civilizado, marcado por determinadas feições urbanísticas. Tal fato na prática custou a se fazer presente na paisagem da cidade, a não ser por algumas marcas como, por exemplo, achegada do calçamento de paralelepípedos na Rua do Ouvidor em 1857 (FERREIRA, 2005, p.81).

Sobre as principais barreiras topográficas da cidade, pode-se elencar a produção de miasmas pela ação dos pântanos e a falta de circulação dos ventos ocasionados pelas montanhas e morros, uma vez que a cidade estava dividida entre as freguesias e inserida no espaço de fundo de vale existente entre eles. Na figura 1, pode-se observar a representação da planta da cidade em 1790, onde os morros existentes a época podem ser facilmente percebidos. Outros problemas relativos o sítio urbano da cidade do Rio de Janeiro estariam ainda relacionados às dificuldades da drenagem de águas pluviais, que deixavam os solos sempre úmidos, devido à proximidade com os lençóis freáticos. Por fim, a população carioca convivia também com o ar infeccioso proveniente da falta do recolhimento de lixo e consequentemente das sujeiras das vias públicas, assim como o tratamento não adequado de esgoto, conforme apontam Carvalho (1990, p.72) e Abreu (1997, p.164).

\section{Figura 1 - Planta da cidade em 1790 com destaque feito pelos autores para a Rua do} Ouvidor.

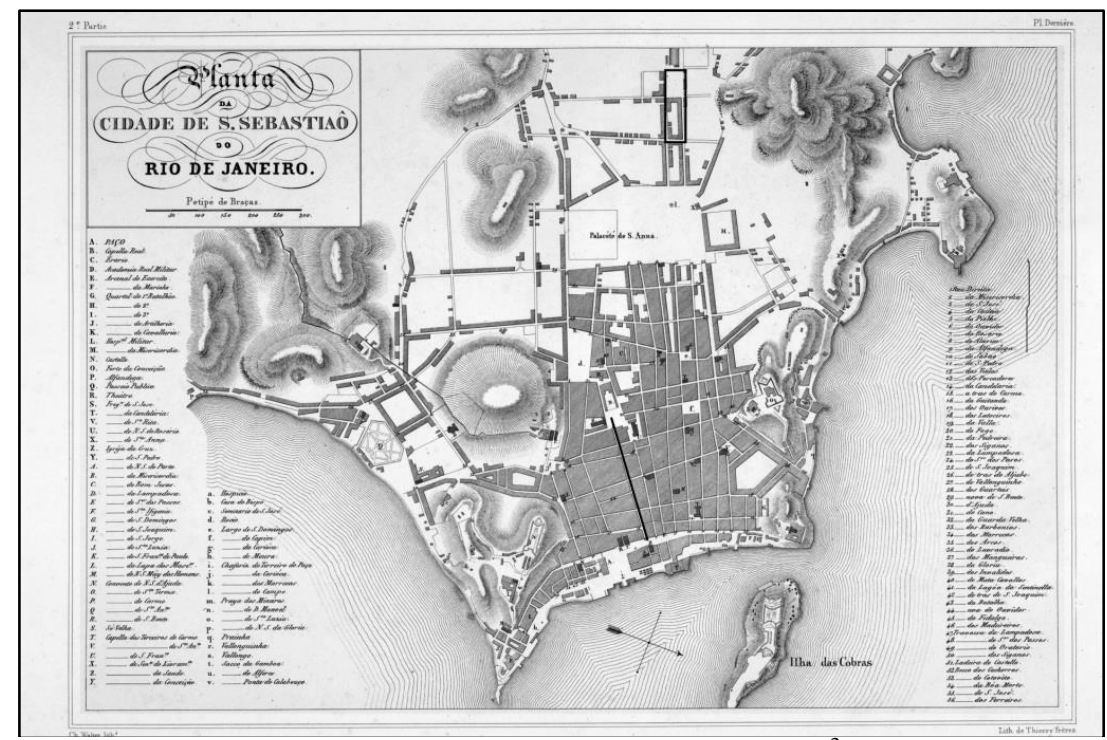

Fonte: Paris: Firmin Didot Frères, $1835^{3}$.

\footnotetext{
${ }^{3}$ Disponível em http://www.brasiliana.usp.br/bbd/handle/1918/624520093
} 
É nessa cidade, em forma de tabuleiro, que está inserida a velha e conhecida Rua do Ouvidor. Uma das ruas mais antigas da cidade, que segundo registros documentais já existia desde a fundação da cidade por Estácio de Sá, em 1567. Sua primeira função como espaço foi de servir como um desvio do mar, pois sua forma era reta em meio às já citadas barreiras naturais, e daí vem seu primeiro nome: Desvio do Mar (MACEDO, 2005, p.9). A rua que hoje é considerada como uma das ruas apertadas do centro antigo já teve seus dias de glórias como a grande concentração de comércio. Sua centralidade extrapolava as questões econômicas. Ali também havia uma concentração de serviços públicos e vários cafés onde as questões políticas e o pensamento de vanguarda eram discutidos.

No período anterior a sua nomeação como Rua do Ouvidor, além dos nomes de Desvio do Mar, teve também os nomes de Aleixo Manuel, em 1590 e Padre Homem da Costa, em 1659. Segundo Gerson (1965, p.63), o nome Aleixo Manuel se refere a um comerciante e cirurgião que ali morava. Já o nome Padre Homem da Costa é em homenagem a um padre que realizou um número considerável de casamentos em todas as freguesias do Rio de Janeiro e que também residia na Rua do Ouvidor (MACEDO, 2005, p.33).

O atual nome da rua tem data de 1780, e tem origem no cargo de Ouvidor-mor dentro da estrutura do Governo-Geral, que a metrópole portuguesa impôs a sua colônia como forma de demonstrar sua soberania e controle das riquezas produzidas. Nesse ano, o Dr. Francisco Berquó da Silveira chegou ao Brasil após ser nomeado Ouvidor e foi “morar à Rua do Padre Homem da Costa, casa de sobrado, que é hoje de número 62-A” (MACEDO, 2005, p.59).

A centralidade da Rua do Ouvidor no espaço urbano do Rio de Janeiro se consolida com a chegada da Família Real portuguesa, em 1808, e as transformações urbanísticas iniciadas nesse período. $\mathrm{O}$ uso desse conceito de centralidade se justifica com a noção de atração de fluxo de pessoas, dinheiro, comércio e serviços "como resultado material acumulado das ações humanas" (SANTOS, 2006, p.69). Para Gerson, "páginas inteiras seriam necessárias para acompanhar, através dela, o desenvolvimento comercial e social da cidade" (GERSON, 1965, p.69), em referência que a rua em questão tem para com a história do Rio de Janeiro e do Brasil e assim, afirmar sua imponência de outrora.

A Rua do Ouvidor passou a apresentar essa característica com a chegada dos comerciantes ingleses logo depois das providências tomadas por D. João quando aqui chegou como a abertura dos portos, fim do embargo e inicio do comércio internacional (GERSON, 1965, p.64). A chegada dos comerciantes ingleses fortaleceu o viés comercial da rua junto 
com os estabelecimentos de origem portuguesa já existente. Os comerciantes franceses datam da chegada da missão francesa após as derrotas de Napoleão Bonaparte e a retomada dos acordos comerciais entre Portugal e França. Segundo Macedo (2005, p.60), é nesse período que a Rua do Ouvidor vai ficar conhecida como a rua francesa, através de diversos comércios de corte e costuras com as mademoiselles francesas e de casas famosas, como a Notre Dame de Paris. Tal fato pode ser comprovado, a título de exemplo, através de notícia de uma casa comercial com produtos franceses para os festejos do carnaval, retirado de importante veículo de informação do século XIX:

GALERIA DE VESTUARIOS CARNAVALESCOS. 37 Rua do Ouvidor 37. Neobey convida à mocidade, amantes dos bailes mascarados, a vir admirar a variada e magnífica novíssima coleção de vestuarios de phantasia, encomendados expressamente ao celebre Moreau de Paris para o carnaval d'este anno. Os apreciadores d'este alegre passatempo acharão n'esta casa tudo que é possível desejar em riqueza, bom gosto e novidade, vestuarios, mascaras, carrancas, narizes, bigodes e collarinhos de todos os gostos, fórmas, tamanhos, feitios, e cores, etc. Enfim, n'esta casa há preciosíssima colleção, encontra-se até zuavos por preços razoaveis. (Diário do Rio de Janeiro, 27 de Janeiro de 1856).

Com base na premissa em que a Rua do Ouvidor apresenta-se como a principal centralidade do recorte temporal analisado, percebe-se que o uso do espaço para usos específicos influencia a composição de um determinado grupo social, assim como o surgimento de manifestações culturais distintas que justificam a criação de organizações espaciais próprias. Dentro da metodologia utilizada, a Rua do Ouvidor apresenta-se como palco principal de eventos e festas no período de permanência da família real, assim como durante o império brasileiro. Na figura 2 pode ser vista a paisagem da rua na composição urbana da cidade durante a segunda metade do século XIX em uma amostra do seu cotidiano. 
Figura 2 - Cotidiano da Rua do Ouvidor no século XIX.

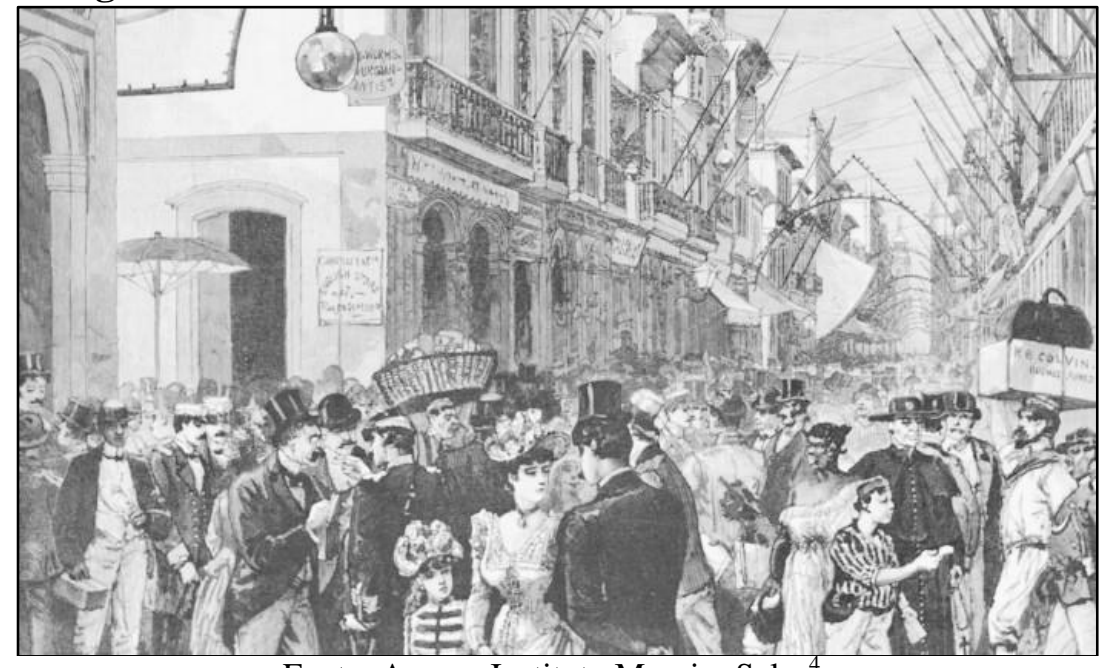

Fonte: Acervo Instituto Moreira Sales ${ }^{4}$.

\section{A CIDADE E SEU CARNAVAL, PROCESSOS E EVOLUÇÕES}

Ao estudarmos o passado de uma cidade, torna-se imprescindível o estudo das práticas e costumes que existiram e ainda existem, mesmo que tenham ocorrido processos de aglutinação ou desaparecimento de certa prática. Para Certeau (1998, p.80), a construção do espaço da cidade faz parte de seu cotidiano, pois é o lugar de transformações e apropriações com novos atributos e objeto de intervenções ao mesmo tempo. Com isso, o carnaval apresenta diferentes produções dos espaços cotidianos pois a produção dos mesmos é um conjunto de operações e não uma simples redução a um objeto carregado de novos significados presentes em cada manifestação carnavalesca.

Os primeiros festejos de carnaval em nosso país vieram junto com os colonizadores portugueses que aqui se instalaram. Macedo (2005, p.25), ao explicar a origem do nome Aleixo Manuel para atual Rua do Ouvidor, narra um episódio de entrudo que segundo as fontes, data do final do século XVI, conforme fragmento abaixo:

No dia seguinte, domingo de entrudo, e do entrudo selvagem e delirante daqueles tempos, era pouco antes das onze horas da noite, quando bateram à porta da casa do cirurgião, e o chamaram a alto bradar em socorro do governador, o venerando Salvador Correia de Sá, que se achava em perigo de morte. [...] (MACEDO, 2005, p.26)

\footnotetext{
${ }^{4}$ Disponível em http://oglobo.globo.com/rio/bairros/cinco-lugares-adorados-ou-detestados-por-machado-deassis-14043216
} 
Esse episódio não é muito diferente do que é abordado por outros autores sobre o festejo do entrudo, que resistiu bravamente às outras manifestações carnavalescas que o taxavam como violento (PEREIRA, 2005, p.92).

$\mathrm{O}$ entrudo era classificado em entrudo familiar e entrudo popular. $\mathrm{O}$ entrudo familiar era caracterizado pela segregação social dentro das residências, uma vez que eram realizados dentro destas através de reuniões sociais propostas pelas classes mais elevadas, como almoços e jantares e no máximo se estendiam até as sacadas e janelas dos casarões, a fim de atingir com projéteis em quem estivesse passando desavisado por debaixo de sua varanda. Ficaram famosos pelos enfarinhamentos, molhadelas e o despejo de limões de cheiro perfumados que eram produzidos e comercializados especificamente nesta ocasião, e usados durante o carnaval como munição dos ataques produzidos pelas molhadelas (FERREIRA, 2004, p.84). O fragmento da notícia abaixo aponta um exemplo desse comércio:

ATTENÇÃO: Na Rua da Lapa do Desterro, número 49, loja, recebem-se as encomendas para limões de cheiro, muito bem feitos e de diversas cores. (Diário do Rio de Janeiro, 21 de Fevereiro de 1852).

A outra maneira de se brincar o entrudo era o chamado entrudo popular, que era considerado como uma forma de se jogar as brincadeiras muito mais brutais e violentas (FERREIRA, 2004, p.89). O lugar das brincadeiras era a rua composta pelos marginalizados quase sempre escravos elou pobres que não detinham o poder de brincar o entrudo dentro das residências, como a classe dominante da sociedade fazia. Esse fato da rua ser apontada como concentração dos marginalizados é resultado das condições naturais que a sociedade impõe em suas lutas de classe reafirmando, assim, que o território "é um compartimento do espaço como fruto de sua diversificação" (SAQUET, 2015, p.27). Os principais projéteis lançados além dos limões de cheiro eram os pós de diferentes naturezas como de polvilho, vermelhão, de sapato, alvaiade e também água da sarjeta, urina e fezes provenientes dos escravos tigres que trabalhavam transportando os dejetos das casas coloniais em locais como a praia de Santa Luzia ou de Dom Manoel, exemplificando as mazelas estruturais da capital, como a falta de rede de esgoto.

Desde a independência do Brasil do poder lusitano, tornou-se recorrente uma negação da herança portuguesa aqui deixada vista comumente como primitiva arcaica e atrasada, que vinha como força contrária à corrente de ser o Brasil uma nação moderna - mesmo que a realidade espacial da capital dissesse totalmente o contrário com problemas existentes. Nesse sentido com os festejos durante o carnaval não poderia ser diferente: o entrudo, 
principalmente o popular, era taxado de selvagem, primitivo e violento. Esta imagem não condizia com a nova realidade socioeconômica do país em que a exportação de matérias primas e importação de manufaturados europeus eram seus pilares (FERREIRA, 2005, p.41).

Eis que a forma encontrada para celebrar o verdadeiro carnaval livre da influência portuguesa foi o modelo dos bailes de máscaras originários de Veneza no século XVI, e fortemente incorporados aos salões franceses pela burguesia ascendente com o período revolucionário que o país vive durante o século XIX, e que se propaga pelo mundo como retrato de festa civilizada e moderna. Os primeiros bailes ocorreram nos anos de 1840 nos principais teatros e hotéis da cidade, como os Teatros São Pedro de Alcântara e São Januário, e os Hotéis Tivoly e Itália. Com a ocupação desses teatros pela prática carnavalesca, há a criação do "conjunto de lugares hierarquizados, conectados a uma rede de itinerários" (BONNEMAISON, 2002, p.99), em outras palavras, a criação de territórios. A partir do texto da na notícia abaixo, pode-se observar com era feita a convocação para um desses bailes:

TIVOLY. Grande Baile Mascarado. Sabbado, 13 do corrente, às 9 horas da noite terá lugar no Pavilhão o primeiro baile mascarado. [...] (Diário do Rio de Janeiro, 12 de Junho de 1846).

Os bailes ficaram famosos pela luxuosidade das ornamentações, diferentes atrações ao longo da noite e principalmente pela implementação do uso de fantasias e máscaras, conforme Moraes (1958, p.51). O costume de se fantasiar e usar máscaras tinha como função a preservação da identidade dos foliões e também para compor a brincadeira do "sabe quem eu sou?". As pessoas saíam perguntando aos demais se os conheciam principalmente as mulheres em que faziam confidências com as vozes disfarçadas para que o outro não conseguisse identificar de quem eram aquelas informações (FERREIRA, 2004, p.112). O aluguel e compra dos trajes para os bailes caíram no gosto da parte mais abastada da população, e foi incorporada pelo comércio da época numa forma de substituir as rendas auferidas pela venda dos limões de cheiro feitos por escravos. O que também pode ser exemplificado através de mais uma notícia de jornal:

PARA BAILES. Mascaras de fina cêra e arame a 1\$; na Praça da Constituição, número 50. (Diário do Rio de Janeiro, 10 de Fevereiro de 1849).

No decorrer dos anos após os primeiros bailes, quando estes deixaram de ser novidade e passaram a ser incorporados no cotidiano carnavalesco da cidade, os transeuntes com 
destino aos teatros se tornaram alvos das molhadelas e da confusão que acontecia nas ruas, desde o arremesso de limões de cheiros a banhos de água suja. Tal fato se pode atribuir a uma herança cultural do entrudo, que se apresentou fortemente como forma de se brincar o carnaval. Pode-se também entender como uma resistência a forte campanha de degradação dessa prática que foi diretamente vinculada a uma postura que remonta a "selvageria" e violência (CUNHA, 2001, p.66). Esse embate para definir o que era o carnaval e o não carnaval e assim, produzir efetivamente os territórios da folia é apresentado em uma ilustração na figura 3.

Figura 3 - Duelo entre Entrudo e Carnaval.

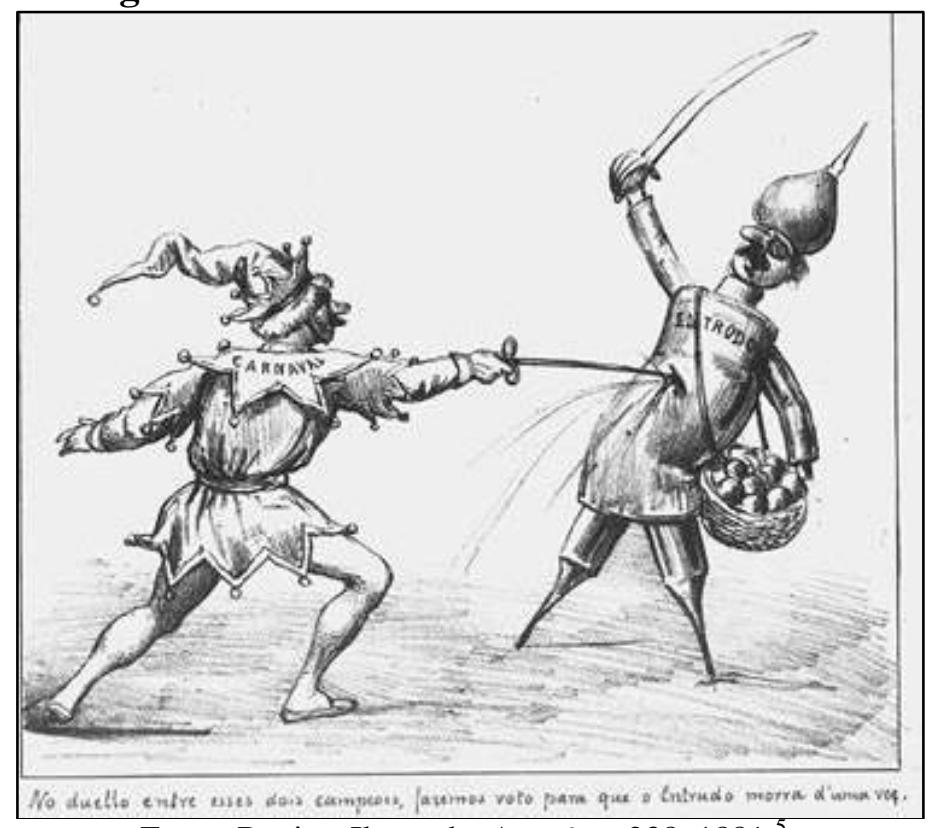

Fonte: Revista Ilustrada, Ano 6, n. 238, $1881^{5}$.

No decorrer dos anos seguintes, os bailes de máscaras foram ficando cada vez mais famosos, assim como a produção de fantasias mais elaboradas e o fortalecimento do comércio das mesmas. Na contramão desse movimento, o entrudo ainda persistia com as suas molhadelas, porém se intensificou o processo de tratá-lo como violento e primitivo pelas parcelas da sociedade que frequentavam esses bailes. Como já abordado, o entrudo não correspondia com a ideia de nação civilizada e moderna que estava se construindo. Com isso, os jornais foram um dos principais mecanismos de propagação para desacreditar o entrudo, como se pode comprovar a partir do seguinte fragmento de notícia:

\footnotetext{
${ }^{5}$ Retirada do acervo da Hemeroteca Digital - Biblioteca Nacional.
} 
Todos reconhecem os grandes inconvenientes que resulta deste gênero de divertimento e, uma grande parte de nossa população o repele como impróprio de um povo que quer ter foro de civilizado [...] (Jornal do Commercio, 01 de Fevereiro de 1860).

\section{AS GRANDES SOCIEDADES DE OUTRORA}

O estudo das práticas que compõem o carnaval aponta que na segunda metade do século XIX surge uma nova forma manifestação. Cabe ressaltar que apesar de cederem espaço para essa nova forma de se festejar o Carnaval, as formas anteriores não desaparecem. Acabam que estas passam a conviver e a se utilizar de formas próprias, ao mesmo tempo em que ocorrem em áreas distintas do espaço da cidade. Com as diferentes ações do homem se produz conteúdo a essas formas espaciais (SANTOS, 2006, p.70). Nessa perspectiva, a análise do carnaval realizado pelas Grandes Sociedades aponta como objeto de estudo a produção de novos espaços para a folia, através de outra concepção e de outra forma de se fazer Carnaval, diferente do que já era praticado tanto pelo entrudo como pelos bailes de máscaras.

A primeira Sociedade Carnavalesca surgiu em 1855, denominada Congresso das Sumidades Carnavalescas. Foi criada como uma associação para criar um conjunto de pessoas para irem juntas aos bailes que eram realizados nos teatros e assim, não receber nenhum ataque do entrudo enquanto realizava seu percurso e também para saudar os foliões que brincavam o carnaval pelas ruas (FERREIRA, 2004, p.128). O costume de se reunir em grupos para compor as sociedades é de origem europeia, compreendido e incorporado às práticas sociais como sendo um modo de vida moderno e civilizado. Esse costume ganhou força dentro das práticas carnavalescas. A notícia de jornal transcrita abaixo aponta o primeiro desfile das Sumidades:

[...] O Congresso das Sumidades Carnavalescas extreou no domingo percorrendo, seus membros, em carros, muitas ruas da cidade: muitos se apresentárão ricamente vestidos, todos com elegância e gosto. [...] (Diário do Rio de Janeiro, 24 de Fevereiro de 1855).

No mesmo período de criação do Congresso das Sumidades Carnavalescas, surgiu também a União Veneziana. Seu nome é uma homenagem aos carnavais de Veneza, em que, junto com os carnavais franceses, surge a ideia de construção do carnaval brasileiro. Conforme Ferreira (2005, p.77) tal fato promoveu a concepção de um carnaval marcado por um viés moderno e civilizado. É a partir daí que se inicia o processo da ocupação das ruas da 
cidade por diferentes sociedades, para a realização dos seus desfiles de fantasias em direção aos teatros ou outros locais onde se realizavam os bailes. As sociedades carnavalescas competiam entre si, mostrando sua importância a partir do número de participantes que teriam em seus bailes. Tal rivalidade era marcada pelas novas surpresas e atrações para os seus desfiles e bailes, que traziam a cada carnaval que se passava. A notícia abaixo exemplifica tal rivalidade nos festejos carnavalescos na cidade do Rio de Janeiro.

Tem logar hoje nos salões do Club Fluminense o baile de phantasia dado pelo Congresso das Sumidades Carnavalescas e no Congresso Fluminense o da sociedade carnavalesca União Veneziana. Ambas as sociedades têm-se esmerado em preparativos que tornarão o presente carnaval muito mais brilhante e animado que nos annos anteriores. Consta-nos que os salões do Club acham-se magnificamente preparados para esta noite. A musica do $1^{\circ}$ batalhão de fuzileiros tocará no terraço durante o baile. (Diário do Rio de Janeiro, 13 de Fevereiro de 1858).

Com o passar dos anos, o Congresso das Sumidades Carnavalescas e a União Veneziana passaram por processos de cisão e foram criando outras sociedades menores que formaram as bases das três Grandes Sociedades Carnavalescas do século XIX: Tenentes do Diabo, Fenianos e Democráticos a partir dos idos anos de 1860. Essas três ficaram famosas pelas personalidades que fizeram parte dos seus grupos e apoio dos jornais da época e também pela continuidade da veiculação dos hábitos modernos e civilizados (PEREIRA, 2004, p.127). O seguinte fragmento relatado abaixo narra à repercussão dos desfiles nesse aspecto:

\footnotetext{
O carnaval, reunindo o povo, ensinando-lhe a elegancia das maneiras, da linguagem, as regras da polidez; despertando nelle o desejo de conhecer as personagens que vê resuscitadas: espalhando-lhe no coração o influxo de um prazer que não exige sacrificio de ninguém, que não se basea em exclusões, mas que pelo contrario toca a todos, é por certo uma idéa que merecia a aceitação que tem encontrado entre nós, e que irá de anno em anno se desenvolvendo e aproveitando todas as circumstancias que possam contribuir para a sua completa realização. (Diário do Rio de Janeiro, 21 de Fevereiro de 1858).
}

As Grandes Sociedades antes de tudo foram fortes instrumentos de atos políticos. Em relação aos atos políticos, foi de grande importância o apoio à causa abolicionista, ajuda financeira a instituições de caridade e também ao movimento republicano. Segundo Pereira (2004, p.125), as Sociedades faziam festas em suas sedes quando estas financiavam a alforria de escravos e assim, fortaleceram o movimento abolicionista. Para os membros das Sociedades, os desfiles tinham como missão educar a população que assistia aos desfiles nas margens e calçadas das ruas, deixando para o centro das ruas o espaço por onde passariam as Sociedades. A seguinte notícia narra a ajuda dos bailes para uma instituição de caridade: 
Os abaixo assignados membros da comissão, nomeada por aviso do governo imperial de 28 de janeiro ultimo, para tratar da realisação dos bailes, que devem ter lugar no próximo carnaval no Theatro Lyrico Fluminense, e de repartir a semma líquida proveniente dos mesmos bailes, pelos 3 estabelecimentos pios de Santa Thereza, dos surdos-mudos, e do collegio da providência [...] (Diário do Rio de Janeiro, 04 de Fevereiro de 1857).

A composição dos desfiles das Sociedades era constituída pelos foliões dividida nos grupos que compunham as Sociedades no geral, por exemplo, os Tenentes do Diabo tinham um grupo chamado de as Ventarolas. Na organização do curso dos préstitos, em primeiro lugar iria à exposição do estandarte da Sociedade e depois iam os grupos divididos entre carros alegóricos, conforme a figura 4, e os foliões fantasiados ao nível da rua entoando as composições musicais para o carnaval do ano, segundo afirma Cunha (2001, p.23).

\section{Figura 4 - Carros Alegóricos utilizados pelas Sociedades no ano de 1883.}

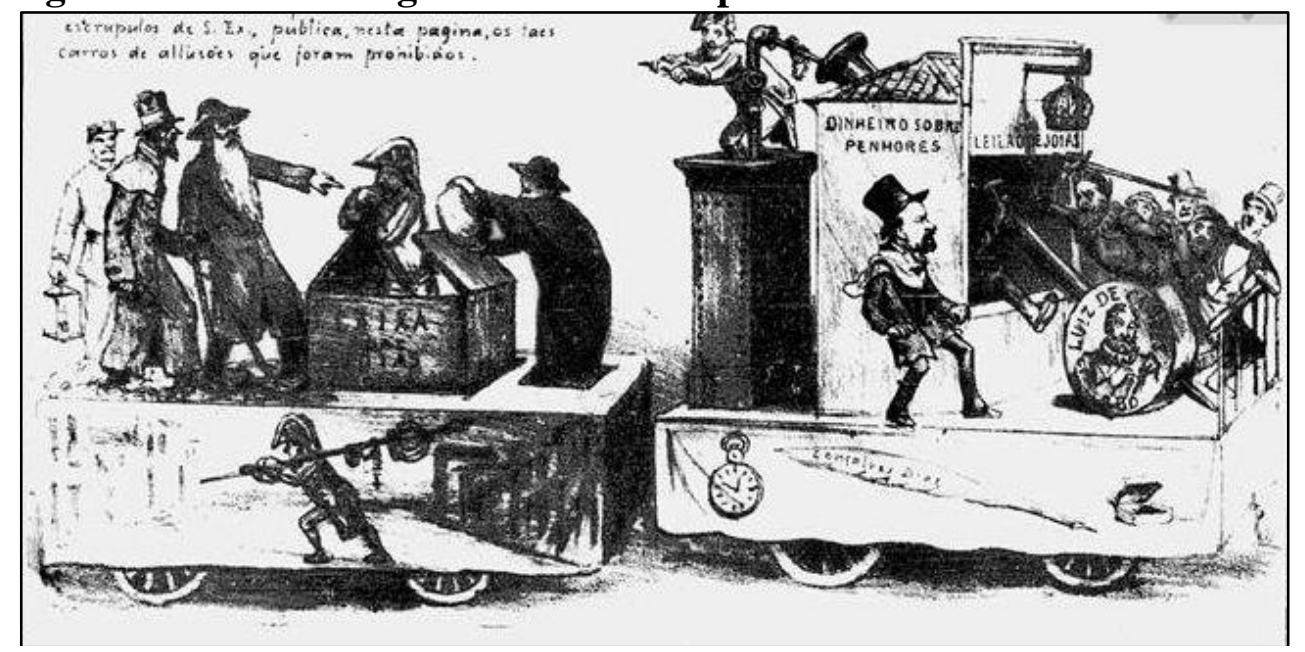

Fonte: Revista Illustrada, Ano 8, n. 331, $1883^{6}$

Vale ressaltar que com o sucesso que estes préstitos passavam a ter ano após ano, surgiram dois dias de desfiles das Sociedades, o domingo e a terça-feira, por exemplo, afirmado na notícia seguinte. Os desfiles do domingo eram os desfiles de crítica, principalmente às ações do governo e de outros aspectos da sociedade, e na terça-feira era o desfile de luxo, onde as Sociedades demonstravam seu luxo e esplendor com a afirmação do carnaval de um país civilizado através dos usos de fantasias suntuosas.

\footnotetext{
${ }^{6}$ Retirada do acervo da Hemeroteca Digital - Biblioteca Nacional
} 
Tenentes do Diabo. Bravo aos Tenentes! Justificou o que tínhamos dito os gloriosos carnavalescos ressurgiram mais fortes e cheios de entusiasmo da grande catastrophe que sofrera ha dias. Em sessão da diretoria realizada de hontem, os Tenentes resolveram festejar o carnaval na rua, apresentando na terça-feira gorda um préstito sumptuosissimo, com carros allusivos e allegorias. No próximo sabbado realiza-se na Caverna o primeiro cottilon deste anno. Bravo aos Tenentes! (Diário do Commercio, 24 de Janeiro de 1889).

\section{A RUA DO OUVIDOR COMO TERRITÓRIO DO CARNAVAL}

A construção de um território determina-se por usos específicos daquele espaço e é fortemente influenciado pelo uso do poder dos grupos que compõem as sociedades. Reconhecer este poder, dos grupos da sociedade, configura desvelar as divisões sociais, econômicas entre outros aspectos em que representam o seu contingente. Trazendo essa discussão para a Rua do Ouvidor nos dias de carnaval, os desfiles das Sociedades traziam esse ar aristocrático durante os seus desfiles e após isso, a rua retornaria ao livre acesso das demais camadas sociais que compunham a sociedade.

Trabalha-se aqui a perspectiva dos diferentes usos da Rua do Ouvidor pelas Sociedades e pelo carnaval popular. Através dessa noção, a Rua do Ouvidor configura-se como um geossímbolo, logo um território carnavalesco através dos processos de territorialização que as diferentes parcelas da sociedade representavam nos dias da folia. $\mathrm{O}$ conceito de geossímbolo refere-se ao uso da função do símbolo no espaço na construção de territórios que levem em consideração a afetividade e significações, e assim a construção de espaços vividos, ou seja, permeados pela cultura (BONNEMAISON, 2002, p.106).

A Rua do Ouvidor, além de atrair os festejos carnavalescos, era a representação dos moldes europeus em terras brasileiras através das lojas de comércio estrangeiras, principalmente as francesas, como já foi abordado neste ensaio na primeira secção. Trazendo para as dimensões espaciais da atualidade, se questiona como uma rua estreita poderia comportar o grande fluxo de pessoas durante o carnaval e no período após ele. A configuração espacial da rua como estreita nos remete como foi à ordenação territorial feita pelos portugueses. Nela, a cidade se apresentava como um produto mental dos mesmos, que consideravam as barreiras topográficas não como empecilhos dentro da ideia de cidades planificadas, mas sim como um elemento a ser incorporado dentro do próprio ordenamento, segundo Abreu (1996, p.149).

Através da situação analisada, a Rua do Ouvidor apresentava-se como o principal espaço do carnaval, desde quando o carnaval propagado pelas elites passou a fazer uso efetivo 
de outros espaços, como as ruas, além dos teatros e suas sedes ou de ficarem reclusos em suas casas com medo dos ataques selvagens do entrudo (CUNHA, 2001, p.57). É notável que outro aspecto relevante da Rua do Ouvidor para a concentração dos desfiles passarem por sua extensão é a concentração da imprensa, tendo em vista que narrava suas glórias nos dias posteriores ao carnaval, conforme exemplo abaixo:

\begin{abstract}
Democráticos. Depois de fazerem o seu passeio e a sua visita às sociedades amigas, recolheram-se ao seu Castello levando o estandarte novo do grupo dos Bonlangistas, que esteve exposto na Glace E'légante, à rua do Ouvidor, e duas bandas de musica militar. No seu trajeto foram saudados pelo povo, que já se acostumou a vel-os cheios de glória nos dias do carnaval: as sociedades co-irmãs, que receberam a visita dos Democráticos, fizeram-lhe esplendidos manifestações vindo recebe-los na rua com musica e os seus estandartes, queimando fogos de bengala. [...] (Diário do Commercio, 18 de Fevereiro de 1889).
\end{abstract}

Outro aspecto relevante ao classificar a Rua do Ouvidor como um território do carnaval é considerar o que acontece com a rua após a passagem das glórias das grandes sociedades. Vale ressaltar que o acesso para ver os desfiles era permitido e após a passagem dos préstitos, as camadas populares tomavam conta do espaço e assim constituíam outra territorialização da rua durante os dias de carnaval em suas práticas culturais, tanto do entrudo como o surgimento de outras manifestações como o Zé Pereira e os Cucumbis, de acordo com Cunha (2001, p.58). Na figura 5 se vê uma representação do carnaval do ano de 1877, tendo no centro os desfiles das Sociedades e nas margens do cortejo, as demais camadas populares.

Com isso, a ocupação do espaço durante os dias festivos apresenta diferentes processos e atores. Dentro dos desfiles das próprias sociedades socorriam diferentes processos e construções e até certa rivalidade durante o carnaval e nos períodos que antecediam e sucediam a folia. Assim, o carnaval apresentava-se como uma manifestação cultural capaz de produzir diferentes territórios no mesmo recorte espacial durante sua duração e através disso, configurar outro sentido à Rua do Ouvidor, além daquele conhecido do cotidiano da cidade. 
Figura 5: Carnaval de 1877.

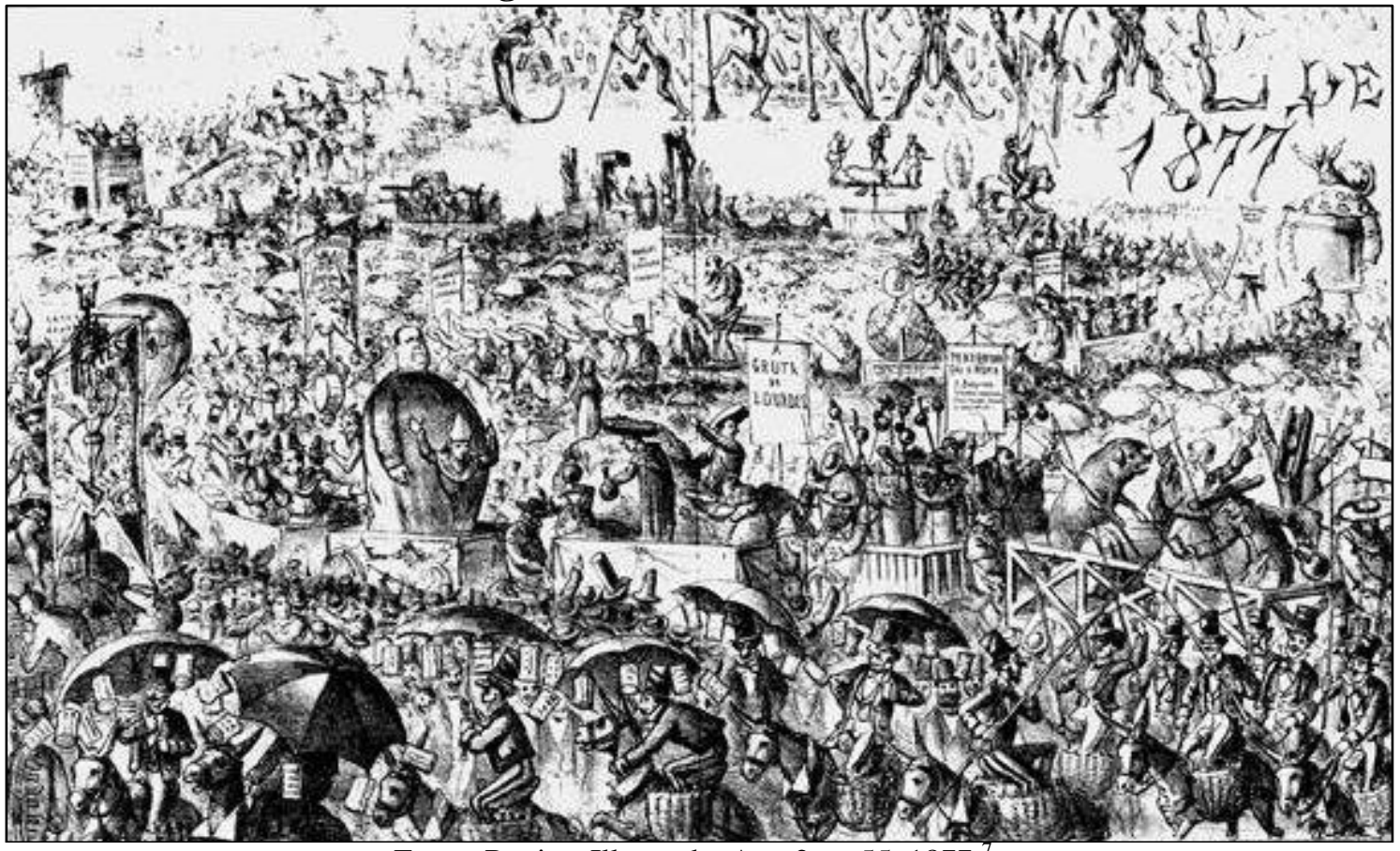

Fonte: Revista Illustrada, Ano 2, n. 55, $1877^{\top}$.

\section{CONSIDERAÇÕES FINAIS}

O presente estudo apresentou a construção de diferentes territórios culturais pelas práticas carnavalescas na centralidade do passado do Rio de Janeiro, sendo a Rua do Ouvidor o principal espaço que apresentava uma territorialidade sazonal a partir dos festejos do Carnaval na segunda metade do século XIX. Foram apresentadas territorialidades distintas e múltiplas que ocorriam durante o carnaval e por diferentes manifestações culturais, síntese da rua durante o carnaval, relacionadas a diferentes raças e classes. Os dias da folia carregavam novos significados e interpretações na produção de novas territorialidades e, assim, aspectos materiais e imateriais na construção das relações sociais.

Aponta-se como etapas seguintes a esse estudo da construção de territórios carnavalescos na Rua do Ouvidor, o estudo aprofundado das Sociedades nos períodos abolicionista, republicano e no pós-proclamação da república, suas mudanças de discursos, novas acepções na composição de seus desfiles e surgimento dos Corsos como uma manifestação da alta sociedade na nova centralidade criada após a abertura da Avenida Central. Outro caminho a ser estudado também são as análises das manifestações de origem popular em oposição às Grandes Sociedades, como os Zé-Pereiras, ainda na Rua do Ouvidor,

\footnotetext{
${ }^{7}$ Retirada do acervo da Hemeroteca Digital - Biblioteca Nacional
}

Sociedade e Território - Natal. Vol. 29, N. 1, p.163 - 182 Jan./Jun. de 2017 
e os Cucumbis e Blocos e seus territórios gerados na Praça XI em busca de novas significações das representações culturais.

\section{REFERÊNCIAS}

ABREU, Maurício de Almeida. Pensando a cidade no Brasil do Passado. In: CASTRO, Iná Elias; CÔRREA, Roberto Lobato; GOMES, Paulo César da Costa (ORGANIZADORES). Brasil: Questões atuais da reorganização do território. Rio de Janeiro: Editora Bertand Brasil, 1996. p. 145 . 184.

Evolução Urbana do Rio de Janeiro. $3^{\text {a }}$ Edição. Rio de Janeiro: Editora IPLANRIO, 1997.

BONNEMAISON. Joël. Viagem em torno do território. In: ROSENDAHL, Zeny. CÔRREA, Roberto Lobato (ORGANIZADORES). Geografia Cultural: Um século (3). $1^{\text {a }}$ edição. Rio de Janeiro: EDUERJ, 2002. p. 83 . 131.

CARVAlHO, Carlos Delgado de. História da Cidade do Rio de Janeiro. Biblioteca Carioca, volume 6, 2ª edição. Rio de Janeiro: Secretaria Municipal de Cultura, 1990.

CERTEAU, Michel de. A Invenção do Cotidiano. $3^{\text {a }}$ edição. Petrópolis: Editora Vozes, 1998.

CUNHA, Maria Clementina Pereira. Ecos da Folia: Uma história social do carnaval carioca entre 1880 e 1920. $1^{a}$ edição. São Paulo: Companhia das Letras, 2001.

DIÁRIO DO COMMERCIO. Rio de Janeiro, 1888 - 1892. Diário. 24 de Janeiro de 1889.

DIÁRIO DO RIO DE JANEIRO. Rio de Janeiro, 1821 - 1879. Diário. 12 de Junho de 1846. 10 de Fevereiro de 1849.

.21 de Fevereiro de 1852.

. 24 de Fevereiro de 1855.

.27 de Janeiro de 1856

. 04 de Fevereiro de 1857.

.21 de Fevereiro de 1858.

.13 de Fevereiro de 1858.

FERREIRA, Felipe. O Livro de ouro do carnaval brasileiro. $1^{\text {a }}$ edição. Rio de Janeiro: Ediouro, 2004.

Inventando Carnavais - O surgimento do carnaval carioca no século XIX e outras questões carnavalescas. $1^{\text {a }}$ edição. Rio de Janeiro: Editora UFRJ, 2005. 
GERSON, Brasil. História das ruas do Rio. $4^{\text {a }}$ edição. Rio de Janeiro: Livraria Brasiliana Editora, 1965.

HAESBAERTH, Rogério. Território e multiterritorialidade: um debate. GEOgraphia. Ano IX, número 17, p. 19 - 46, 2007.

JORNAL DO COMMERCIO. Rio de Janeiro, 1827 - 2016. 01 de Fevereiro de 1860

MACEDO, Joaquim Manuel de. Memórias da Rua do Ouvidor. $1^{\text {a }}$ Edição. Brasília: Senado Federal, 2005.

MORAES, Eneida de. História do Carnaval Carioca. $1^{\text {a }}$ Edição. Rio de Janeiro: Editora Civilização Brasileira, 1958.

PEREIRA, Leonardo Affonso de Miranda. O carnaval das letras - Literatura e folia no Rio de Janeiro do século XIX. 2a edição. Campinas: Editora Unicamp, 2004.

SANTOS, Milton. A Natureza do Espaço: Técnica e Tempo, Razão e Emoção. $4^{\text {a }}$ Edição. São Paulo: EDUSP, 2006.

SAQUET, Marcos Aurélio. Abordagens e concepções de território. $4^{\text {a }}$ edição. São Paulo: Outras Expressões, 2015.

SOUZA, Marcelo Lopes de. Os Conceitos Fundamentais da Pesquisa Sócio - espacial. $1^{\text {a }}$ edição. Rio de Janeiro: Editora Bertrand Brasil, 2013.

Recebido em Março de 2017

Aprovado em Junho de 2017

Publicado em Agosto de 2017 